Voix et Images

\title{
Gabrielle Roy et la critique au féminin
}

\section{Lori Saint-Martin}

Volume 20, numéro 2 (59), hiver 1995

Archéologie du littéraire au Québec

URI : https://id.erudit.org/iderudit/201176ar

DOI : https://doi.org/10.7202/201176ar

Aller au sommaire du numéro

Éditeur(s)

Université du Québec à Montréal

ISSN

0318-9201 (imprimé)

1705-933X (numérique)

Découvrir la revue

Citer cet article

Saint-Martin, L. (1995). Gabrielle Roy et la critique au féminin. Voix et Images, 20(2), 463-466. https://doi.org/10.7202/201176ar d'utilisation que vous pouvez consulter en ligne.

https://apropos.erudit.org/fr/usagers/politique-dutilisation/ 


\section{Gabrielle Roy et la critique au féminin}

Lori Saint-Martin, Université du Québec à Montréal

Au terme d'une longue bataille juridique, les Éditions du Boréal l'ont emporté sur les Éditions Stanké: seules désormais elles auront le droit de publier les œuvres de Gabrielle Roy, sûrement, avec Anne Hébert, la mieux connue et la plus aimée des romancières québécoises classiques. Paraissent donc, coup sur coup, nombre d'œuvres ${ }^{1}$ (dont certaines, comme Bonbeur d'occasion, étaient devenues introuvables), imprimées sur du beau papier, aussi fin et blanc qu'était grossier et brunâtre celui de Stanké. Les couvertures reprennent toutes le même format: une bande blanche en haut portant le nom de Gabrielle Roy et le titre de l'œuvre, un trait rouge, et la reproduction d'un tableau d'artiste canadien ou québécois. Plusieurs de ces tableaux entretiennent avec l'œuvre un rapport direct qui établit un dialogue peinturelittérature parfois amorcé déjà du vivant de Gabrielle Roy (La Petite Poule d'eau, de Jean-Paul Lemieux, Sans titre ou la montagne secrète, de René Richard), parfois suggéré par l'éditeur (Neige à Saint-Henri d'Allan Harrison pour Bonbeur d'occasion, Région de Charlevoix, baie Saint-Paul de Marc-Aurèle Fortin pour Cet été qui chantait).

Comme Gabrielle Roy avait revu ses œuvres avant de mourir, la "nouvelle édition" qu'annonce Boréal ne comporte aucune modification 
de fond. Quelques erreurs que reproduisait Stanké depuis toujours (Florentine qui allume une cigarette demande à Rose-Anna: "Ça te fais rien, sa mère?") ont été corrigées, alors que certaines sont restées (le malheureux "je [...] voyait" de la page 21 de La Route d'Altamont) et que d'autres, nouveau travail de typographie oblige, ont échappé aux correcteurs (y compris dans l'utile bibliographie, identique d'un livre à l'autre, et donc reprenant les mêmes fautes). Sans doute est-il heureux que les textes de l'un de nos écrivains les plus importants soient publiés par une seule maison d'édition au lieu d'être éparpillés comme ils l'étaient auparavant (Boréal détenant les droits des œuvres les plus tardives et des inédits dont plusieurs sont à paraitre); sans coûter beaucoup plus cher, la version Boréal respire une qualité et une élégante sobriété, absentes de la collection "Québec 10/10" de chez Stanké.

Cette nouvelle édition de nombreuses ouvres de Gabrielle Roy offre l'occasion de s'interroger sur le rapport qu'entretenait l'auteure avec le genre littéraire. Ici, l'éditeur est intervenu en ajoutant dans plusieurs cas une mention générique absente des éditions antérieures. Passe encore que Rue Deschambault et La Route d'Altamont soient considérés comme des romans (un peu comme Lives of Girls and Women d'Alice Munro). Mais voilà qui est bien moins évident pour Ces enfants de ma vie, livre de portraits, dont le fil conducteur essentiel est la présence dans chaque texte de la même narratrice, ancienne enseignante qui se rappelle ses élèves d'autrefois. S'il s'agit là d'un roman, on pourrait en dire autant de Cet été qui chantait, dont l'unité de composition est au moins aussi forte (on a affaire cette fois à de petits tableaux de la campagne de Charlevoix, reliés par le regard mélancolique d'une narratrice éprouvée par le deuil), mais qui porte, lui, la mention "récits". Au lieu d'y voir une erreur de l'éditeur - ces questions sont des plus épineuses -, il faudrait chercher à savoir comment, sans éclat et sous des allures trompeuses d'extrême simplicité, Gabrielle Roy redéfinit, au fond, les genres littéraires, non pas en les contestant avec fracas, mais en les réinventant de l'intérieur.

\section{***}

Ces dernières années, les études critiques consacrées à l'œuvre de Gabrielle Roy s'affinent et se diversifient. En plus des études thématiques de toujours, paraissent maintenant des analyses stylistiques, sémiotiques, psychanalytiques, extrêmèment nuancées. Tous les critiques s'accordent à reconnaître la complexité, les ambivalences, la richesse de composition d'une œuvre que même ses plus fervents 
admirateurs ont longtemps associée à la simplicité, voire à une certaine spontanéité un tantinet naïve. Apparaît notamment, depuis peu, une nouvelle approche susceptible de renouveler en tous points la critique régienne: les lectures effectuées à la lumière de la critique au féminin. On sait, d'après les entrevues qu'a données Gabrielle Roy, qu'elle a appuyé toute sa vie les visées du mouvement féministe. Dès Bonbeur d'occasion, elle s'intéresse non seulement aux relations entre les classes sociales, mais aussi aux rapports de pouvoir qui se nouent entre les sexes. Son analyse est le pendant romanesque de celle qu'a effectuée Simone de Beauvoir, sur le plan théorique, dans $L e$ Deuxième Sexe $(1949)^{2}$ : même attention accordée au conflit entre la maternité et la réalisation de soi, à l'aliénation de la femme qui accepte de se faire objet du désir de l'homme (Florentine qui attend Jean), à l'impuissance sociale des femmes. Plus généralement, on peut dire que Gabrielle Roy devance et annonce l'ensemble des théories féministes des années soixante-dix et quatre-vingt. Par exemple, sa vision du rapport mère-fille comme pivot de l'identité féminine est celle-là même qu'énonceront Nancy Chodorow, avec ses "frontières mobiles du moi féminin ", et Carol Gilligan, pour qui les femmes sont liées à une "éthique de la sollicitude". Elle est proche encore des échanges de rôles fluides entre mère et fille que préconise Luce Irigaray $^{3}$. La vision qu'a Rose-Anna, dans Bonbeur d'occasion, d'une solidarité à venir entre femmes du monde entier, toutes victimes de la guerre, annonce celle d'une Sara Ruddick, pour qui les mères de famille peuvent être à l'origine d'un nouveau pacifisme ${ }^{4}$. On pourrait multiplier les exemples; entre autres; toute la question du rapport au genre serait à reprendre du point de vue de la critique au féminin ${ }^{5}$.

La lecture au féminin est donc l'une des tendances les plus fécondes de la critique régienne actuelle ${ }^{6}$. Grâce aux études réalisées dans cette optique, on verra bien que Gabrielle Roy fut non seulement une pionnière du roman urbain moderne au Québec, comme on le reconnaît depuis toujours, mais aussi une devancière et un modèle en matière de réflexion féministe et d'écriture au féminin. L'étónnante modernité de cette ouvre ne ressort jamais aussi clairement qu'à la lumière de la critique au féminin.

1. Sont parus en 1993-1994 les titres suivants: Bonbeur d'occasion, La Petite Poule d'eau, Rue Deschambault, La Montagne secrète, La Route d'Altamont, Cet été qui chantait, Un jardin au bout du monde, Ces enfants de ma vie, tous dans la collection "Boréal compact".

2. Voir Lori Saint-Martin, "Simone de Beauvoir and Gabrielle Roy: Contemporaries Reflecting on the Status of Women *, Simone de Beauvoir Studies, $\mathrm{n}^{\circ} 10,1993$, p. $127-139$. 
3. Voir Nancy Chodorow, The Reproduction of Mothering: Psychoanalysis and the Sociology of Gender, Berkeley, University of California Press, 1978; Carol Gilligan, In a Different Voice, Cambridge, Harvard University Press, 1982; Luce Irigaray, Le Corps-à-corps avec la mère, Montréal, Pleine Lune, 1981. Pour une lecture détaillée de Gabrielle Roy effectuée à la lumière de ces théories, se reporter à Lori Saint-Martin, «Mère et monde chez Gabrielle Roy *, Lori Saint-Martin (dir.), L'Autre Lecture. La critique au féminin et les textes québécois, tome I, Montréal, XYZ éditeur, coll. «Documents *, 1992, p. 117-137.

4. Voir Sara Ruddick, Maternal Thinking: Toward a Politics of Peace, New York, Ballantine, 1989.

5. Voir par exemple Agnès Whitfield, •Gabrielle Roy's Cbildren of My Heart or Portrait of The Artist as a Young Woman", Janice Morgan et Colette T. Hall (dir.), Redefining Autobiography in Twentietb-Century Women's Fiction, New York, Garland, 1991, p. 209-225.

6. Voir aussi les subtiles analyses de Nicole Bourbonnais, *Gabrielle Roy : la représentation du corps féminin*, Lori Saint-Martin (dir.), op. cit., p. 97-116, et "Gabrielle Roy : de la redondance à l'ellipse ou du corps à la voix ", Voix et Images, vol. XVI, $\mathrm{n}^{\circ} 1$ (46), automne 1990, p. 95-109. 